\title{
The Effect of Stakeholder Involvement on Legislative Duration: Consultation of External Actors and Legislative Duration in the European Union
}

\section{Anne Rasmussen and Dimiter Toshkov}

Version 21.12.2012 (pre-print, pre-proofs)

\begin{abstract}
Despite the increased use of stakeholder consultations, little is known about their impact on the legislative process. We examine how consultation of external actors during policy preparation affects decision making duration and efficiency. We test our predictions on EU legislative decision making and we find that whereas stakeholder consultations in policy preparation may increase the democratic legitimacy of decision making, they result in efficiency losses in the subsequent legislative processes. Hence, rather than smoothing the way for quick legislative reconciliation, consultations increase the transaction costs of subsequent bargaining by prolonging the time needed to form the necessary coalitions and reach legislative deals. However, despite the proliferation of different tools for involving external actors, we find no differences in legislative speed between open and restricted consultations.
\end{abstract}

\section{Keywords}

co-decision, consultation, decision making, interest groups, legislative duration, survival analysis, 


\section{Introduction}

Consultation of the public in the preparation of policy is one of the core values of modern democratic societies (Abelson et al., 2003; Delli Carpini et al., 2004; Paterman, 1970). Over the years many different mechanisms of hearing the public in the course of legislative decision making have developed (Bishop and Davis, 2002). These mechanisms provide a venue for the public to voice its concerns to the decision-makers, and they imply a varying degree of stakeholder involvement. Sometimes citizens participate directly in these exercises. Other times, their demands are channelled through intermediaries, such as interest groups, committees and advocacy coalitions that forward the concerns of the citizens to the decision-makers. The various mechanisms of consultation allow for the citizen demands to be aggregated and passed on to the political system either directly by the citizens themselves or via non-elected representatives.

Despite the importance and proliferation of different mechanisms for hearing the public in democratic political systems, we know little about their impact on legislative decision making. Public consultation, in its various manifestations, is supposed to increase input legitimacy by allowing for a close match between the will of the public and public policy, and to enhance the output legitimacy of rules by designing effective solutions to social problems ${ }^{1}$. However, public consultation might imply a trade-off between legitimacy and efficiency. Involving different stakeholders and the public at large could protract, delay, or block decision making ${ }^{2}$. In debating the European Commission's (Commission) 2001 White Paper on European Governance, the European Parliament (EP) for example spoke of "the risk of an escalation in consultation" which might be incompatible with the Commission's goal of "reducing the long delays associated with the adoption and implementation of Community rules" (European Parliament, 2001, 8).

In the article, we explore the impact of consulting the public on the efficiency of decision making by focusing on its effect on the duration of the legislative process. We investigate whether public consultations increase the time it takes for a law to be adopted and whether the various institutional forms of consultation moderate this relationship. Responding to the public in a timely fashion is important for decisionmakers. The public does not simply have preferences for specific policies but also for when such policies should be delivered. As time lapses such policies may no longer serve as solutions to the problems they were supposed to address, or the preferences 
of the public might have changed. Moreover, a given political system cannot necessarily afford spending an indefinite time on any single piece of policy, since this creates a risk that it will not be able to deliver in other areas.

Based on the literature on interest groups and legislative duration we develop a set of expectations about the linkage between external actor involvement and legislative duration and test these predictions on a new dataset on legislative decisionmaking in the European Union (EU). The EU is a political system where consultation of external stakeholders plays a particularly prominent role (Lindberg et al., 1998) but where little research has been made on how these stakeholders affect the legislative processes in which they are involved. Over the last decade, a substantial body of literature on EU interest representation has emerged (for research overviews, see e.g. Beyers et al., 2008; Coen and Richardson, 2009; Eising, 2008; Greenwood, 2011). However, there is a lack of studies of interest group influence on procedural aspects of decision making and no studies of their impact on legislative duration.

The data that we use in the empirical analysis covers the period 2004-9 and combines human-assisted coding of the external actor involvement in legislative preparation with automated data collection from the EP's Legislative Observatory and PRELEX databases to derive data on the existence and type of consultations during legislative preparation and legislative duration. Our results show that consultation of external stakeholders in the phase when legislation is prepared slows down the subsequent legislative process rather than making it more efficient. When external actors are involved in preparing the legislative dossiers, the transaction costs of bargaining go up and the decision-makers need more time to form the necessary coalitions to reach deals in the subsequent legislative processes. This conclusion holds irrespective of which kind of consultative mechanism is used to prepare legislation and when we control for different factors that relate to the political importance and controversy of the legislative dossiers. Surprisingly, we see that, despite the proliferation of different tools for hearing the public and the initial fears of the EP, legislative procedures involving open consultations are not significantly more timeconsuming than restricted ones. 


\section{Stakeholder involvement in the EU}

Many different institutional mechanisms of hearing the public have been developed in modern liberal democracies (Bishop and Davis, 2002). Such mechanisms range from exercises where everyone can participate, such as open online consultations and conferences, to restricted types such as written consultations of specific types of actors or hearings of advisory committees. A broad range of participants, including private individuals, interest groups, companies, and public authorities might be involved in consultative exercises. Since we are not only interested in the impact of involving external participants as such, but also in how different forms of involving them affect legislative duration, we theorize and include data on different mechanisms of consultation. We use either the terms "stakeholders" or "external actors" when we refer to the participants as a whole ${ }^{3}$.

The EU puts a lot of efforts into involving external interests in the preparation of EU legislation. Roughly one per cent of the EU budget is specifically allocated to promoting the interests of civil society in EU decision making, and a series of mechanisms exist to involve external interests in the early phases of the decisionmaking processes. The special construction of the EU political system is one where national parties do not have the option to act as transmission belts between the demands of the citizens and the decision-makers as they do in many national political systems (Andersen and Eliassen, 1993; Gaffney, 1996; Lindberg et al., 1998; Mair, 2006). The EU's founding documents explicitly state that "Before proposing legislative acts, the Commission shall consult widely" (Article 2, Protocol on the application of the principles of subsidiarity and proportionality, Treaty of Lisbon). Consultation helps the Commission to obtain valuable expertise necessary for it to produce legislative drafts in a situation where its own resources are limited. It also helps the non-democratically elected Commission bureaucracy to increase the democratic legitimacy behind its proposals (Commission, 2002b, 5) and can make the implementation of these policies at the national level smoother.

Since the beginning of the $21^{\text {st }}$ century, the Commission has launched a series of initiatives to improve European governance (Commission, 2001) and achieve better regulation $(2002 \mathrm{a}, \mathrm{b})$. Consultations do not systematically take place on all pieces of legislation but are usually standard with regard to initiatives subject to an extended impact assessment, i.e. those that result in substantial economic, environmental and/or social impact on a specific sector, have a significant impact on major interested 
parties and represents a major policy reform in one or several sectors" (Commission, 2002b, 15).

Consultations can take various forms ranging from hearing of the Commission's own expert committees to online consultations in which the general public can participate. In case the Commission has conducted consultations on a proposal, the activities undertaken are usually described in an initial section of the legislative proposal under the title "Consultation of Interested Parties". Our reading of these sections in more than 250 proposals reveals at least the following types of consultative exercises: online consultations; forums, conferences and seminars; restricted consultations; consultation of management and labour representatives; and consultation of EU agencies and institutions.

Online consultations are open to everyone including interest groups, public actors and individual citizens. Calls for consultations are published on most of the Commission DGs' websites, and the Commission has set up a single access point for these consultations called 'Your Voice in Europe' (http://ec.europa.eu/yourvoice/ consultations/). In the beginning of each consultation phase, the Commission presents an initial policy document. Subsequently, interested parties are given a period of time to respond in writing. Typically the Commission finishes the process by outlining what the number of responses was and explaining how it has taken the presented views into account in its final proposal.

Another way to involve external interests is by organizing various meetings such as forums, conferences and seminars. The aim of forums is typically to bring stakeholders and Commission staff together. Examples include The European MultiStakeholder Forum on Corporate Social Responsibility and the Pension Forum. The participants in these consultations are mostly peak-level civil society and economic organizations with EU-wide membership. DGs typically organize public conferences and seminars that are in principle open to all types of interests, even though civil society organizations are generally more likely to be involved than individual citizens.

Restricted consultations include consultations of the Commission's own expert committees. The Commission Register of Expert Groups provides summary information about the composition of the expert groups, DG affiliation and tasks. The groups can have a temporary or permanent status and may include academics, different interest groups and public authorities (Gornitzka and Sverdrup, 2008; Gross 
and Rasmussen, 2012). They are created through a legislative act or directly by the Commission services, according to its policy input needs.

Another type of restricted consultation involves collecting input from management and labour, which according to the Treaty establishing the European Community (Articles 154-155) is necessary with regard to social policy. They can be compared to consultations of other EU institutions (such as i.e. the Economic and Social Committee (ESC) and the Committee of Regions (CoR)). Again, the Treaty requires the Commission to consult these in specific policy areas.

\section{Stakeholder involvement and legislative duration}

The new tools for involving civil society at the EU level are likely to have contributed to expanding the number of active interests represented at EU level in recent decades (Greenwood, 2011; Kohler-Koch, 1994). Not surprisingly, the study of EU interest representation has therefore also attracted increased attention (for overview, see Beyers et al., 2008; Coen, 2007; Eising, 2008). A considerable body of literature has emerged and our knowledge of EU interest representation is much more sophisticated now than it was a few decades ago. At the same time, there are still gaps in this literature. Rather than large-n analyses of the EU interest group population, studies of particular policy areas, specific institutions or group types have been prominent (Bouwen, 2004; Greenwood et al., 1992; Wolfgang Streeck et al., 2006). Moreover, the literature has tended to focus on examining interest group access and strategies rather than the outcomes of these efforts (see e.g. Bennett, 1997; Coen, 1997; Eising, 2007; König et al., 2007). More recently scholars have started tackling the issue of interest group influence and lobbying success by systematically examining these in specific policy issues (see e.g. Klüver, 2011, forthcoming; Mahoney, 2008; Schneider et al., 2007). However, there is still a lack of EU studies that examine the effect of interest group involvement on procedural aspects of these decision-making processes, just as there is a lack of such studies in the interest group literature in general. A few analyses, e.g. by Gray and Lowery, examine how properties of interest group populations (such as their size/density and diversity) affect the introduction, enactments and the ratio of bill enactments to introductions (1995; 2000). They find that it is harder to get legislation passed in US states which have a high number of groups that are not very diverse. Moreover, a recent paper (Toshkov et al., forthcoming) examines whether legislative production in the EU systems follows or 
precedes increases in the density of the EU interest group population. However, to the best of our knowledge, so far no one has tried to link characteristics of external actor involvement in legislative decision making to legislative duration.

We have already pointed out that the duration of the legislative process is an important aspect of policy responsiveness in its own right. Political responsiveness is not only about delivering certain policy outputs to the public but also about doing so in a timely fashion at a stage where these political solutions still meet the needs they are supposed to address. As time lapses such policies may no longer serve solve the original problems or the preferences of the public might have changed. Moreover, a given political system will need to deliver a range of different policies to the public. Therefore, spending an indefinite time on any single piece of policy creates a risk that it will not be able to deliver in other areas. In order to know whether legislators are really responsive to the demands of external actors, we therefore need to know not only whether they provide more outputs when these stakeholders are involved, but also whether involving stakeholders affects the speed with which decision-makers respond with such outputs.

We therefore set out to theorize about the relationship between external stakeholder involvement and speed. The literature on decision-making speed in the EU (Golub, 1999, 2007, 2008; Golub and Steunenberg, 2007; Klüver and Sagarzazu, 2011; König, 2007, 2008; Rasmussen and Toshkov, 2011; Schulz and König, 2000; Toshkov and Rasmussen, 2012) may offer some implicit ideas about this relationship One of the key ideas discussed is that preference heterogeneity between the actors involved may affect EU legislative duration. In this light, it is surprising that this literature has not paid attention to consultation of external actors as a determinant of legislative duration. All things equal, we would expect the number of active external interests to add to the number of voices represented in a given case and/or to affect the weight attached to these different voices during the negotiations. Moreover, examining the effect of external actor involvement on legislative duration should be particularly relevant in the EU political system, which puts an emphasis on consulting civil society in legislative preparation.

The first question that concerns us is about the overall effect of involving external actors in legislative preparation on duration. It is possible to imagine two contradictory scenarios. First, we should consider that involving external actors can decrease duration. Pluralists emphasize that in a representative democracy interest 
groups serve an important function because they act as transmissions belts or gatekeepers between the views of the citizens and the decision-makers (Easton, 1971). In this way, groups can be seen as an important part of the machinery of government, which helps ensure that the demands of the citizens can be aggregated and passed on to the political system (Dahl, 1961; Truman, 1971). The alternative is one where legislators would have to deal with all citizens on an individual basis, which would increase the transaction costs of legislative bargaining considerably and require a greater time investment to resolve matters.

Another reason why stakeholder involvement in legislative preparation might decrease legislative duration is that such preparation might help resolve a range of conflicts before proposals reach the legislative process. If legislative proposals are better prepared, they may be less controversial once introduced, which could help reduce the transaction costs of bargaining considerably and speed up legislative matters ${ }^{4}$.

Alternatively, several arguments can be presented against the idea that external actor involvement in legislative preparation speeds up matters. Most importantly, even if certain external actors, such as interest groups, may help aggregate the concerns of citizens, the alternative to group involvement is unlikely to be a version of direct democracy where all citizens appear and voice their concerns to decisionmakers on an individual basis. Moreover, whereas involvement of external actors may help clear issues before the legislative process it could also have exactly the opposite function. It may bring a high number of issues to the attention of decision-makers, which could increase the time they need to resolve matters later on. Hence, according to so-called neo-pluralist scholars (see e.g. Heinz et al., 1993; Salisbury, 1992; Walker, 1983) having more active interests should make it more difficult (and thus also more time-consuming) to enact legislation. These scholars point out how having a greater number of actors involved increases the risk that legislation gets delayed or even blocked because of the greater difficulty involved in forming coalitions. As emphasized by Gray and Lowery, "more and more interest organisations strangle their collective ability to influence legislators" (1995: 548). The underlying logic behind this argumentation is that when a high number of interests are mobilized, preference heterogeneity is also expected to be higher because the groups are likely to represent different views and introduce new voices in the policy processes. 
An exception could be a situation without competition between groups. Some interest group scholars have, in fact, hypothesized a positive association between the number of interest groups and regulatory activity (see e.g. Coughlin et al., 1990; Mueller and Murrell, 1986; Olson, 1982). Their idea is that groups do not necessarily have the same preferences but could engage in some sort of logrolling where each group would get the legislation it prefers. The net result is that we would not necessarily expect interest group involvement to prolong matters if competition between them is limited and they simply divide the pork between them.

However, recent interest group research has demonstrated that there is typically considerable conflict among groups and that it is not the case that they operate in isolated policy niches (see e.g. Gray and Lowery, 2000; Heinz et al., 1993; Salisbury, 1992). In a situation with high preference conflict, we know from spatial decisionmaking models that the gridlock interval without a policy preferred to the status quo is large. Even in such a situation, a deal is usually brokered by offering a compromise to unsatisfied veto players or providing them side-payments. However, if the scope of conflict increases because of interest group involvement negotiations can be expected to last longer (Klüver and Sagarzazu, forthcoming; König, 2007; Schulz and Konig, 2000). Our first hypothesis is therefore that:

H1: Legislative proposals where external actors are consulted in the preparation of legislation have a longer duration than those where such actors are not involved.

The second sets of questions of relevance to a study of how external actor involvement affects duration is not simply whether involvement has an effect as such, but how the form through which external actors are consulted can affect the time decision-makers need to agree on legislation. The key distinction we make is between forms of consultation that offer open and unrestricted access and those where access is restricted to specific types of individuals and organizations. These different types of consultation may not have the same effect on duration because they are likely to 1) contain a different number and range of represented interests, 2) include participants with different skills and degrees of familiarity with consultation exercises and 3) be conducted in a different manner.

First, online consultations and open conferences involve a higher number and more diverse group of actors than consultations that only gather information from a 
restricted number of actors (for example consultations of expert committees). The first type of consultation enables all individuals, companies, interest groups, etc. to voice their concerns on a given matter. This may help decision-makers to ensure that everyone gets a chance to react, but it may also mean that they are faced with having to process inputs from a very high number of diverse participants. Instead, restricted consultations of a limited number of experts might involve considerably lower transaction costs for the decision-makers when they subsequently have to reach a compromise. Settling matters with a few influential, representative interests that are not too diverse reduces the transaction costs of bargaining for the politicians and bureaucrats. Extrapolating from neo-pluralist reasoning, we would expect that the difficulty of forming coalitions on a piece of legislation should generally be greater in a dense, open consultation (see e.g. Heinz et al., 1993; Salisbury, 1992; Walker, 1983). This implies that the risk that legislation gets delayed when open consultations are conducted should also be greater then with restricted consultation. The more actors that are active, the greater the transaction costs involved in reaching a compromise.

Not just the sheer number but also the high diversity of represented interests which can be expected in an open consultation exercise may result in legislative delays. The greater the degree of diversity is, the greater the potential for conflict between these actors (Salisbury, 1992). Our main reason for drawing this expectation is that the finding from existing interest group research that different group types do not operate in isolation from each but typically in a setting with a considerable degree of conflict (see e.g. Heinz et al., 1993; Salisbury, 1992). When such conflicts between different types of stakeholders exist, we would expect diversity to affect duration negatively. In sum, it should be harder (and thus slower) to adopt legislation when a broad range of interests is involved in open consultations and a greater set of different views need to be accommodated.

Second, open consultations might result in longer delays than restricted ones, not because of the overall differences in the number and diversity of represented interests between these two types of consultation, but because of differences in the skills and degree of familiarity with consultation of the actors involved in them. Here we expect that the selected actors involved in restricted consultations, i.e. those allocated seats on advisory committees or given other types of privileged access to voice their views, have a higher chance of contributing to reducing transaction costs 
and reaching legislative deals in a fast manner than the average participant in an open consultation. One of the philosophies behind a corporatist system where a strong relationship is established between the state and a narrow set of specific interest groups (typically capital and labour) by using different forms of restricted consultation is exactly that this is a more effective way of taking decisions (Schmitter, 1979). The privileged interests may be selected for different reasons, such as their degree of expertise and the kind of interests they represent. No matter what, they are likely to be experienced brokers of legislative deals, which should increase the chance that having them on board early on smooths the way for subsequent legislative compromises (Kenworthy, 2003; Schmitter, 1979; W. Streeck and Kenworthy, 2005). In contrast, open consultations may be much more complicated. Here, the decisionmakers have no control of which types of actor they need to deal with, and it is likely that the average participant in an open consultation has much less technical expertise and bargaining expertise.

Third, the format of open as opposed to restricted consultation might also matter. Legislative deals following restricted consultation may be easier to reach, not because they involve fewer and a less diverse set of actors with more expertise, but simply because of the way these consultations are conducted. Needless to say the exact format of an open and restricted consultation might vary as our empirical background made clear. However, a restricted consultation is more likely to take place in an interactive environment where decision-makers and external interests are directly confronted with each other (Bishop and Davis, 2002). Such restricted consultations are therefore more likely to provide a setting allowing for direct exchange between decision-makers and external interests where they can openly negotiate and deliberate. In contrast, the most frequent form of involving external interests, i.e. written consultation procedure, consist of one-way communication from external interests to decision-makers without the option for an instant reaction or any reaction whatsoever. When it comes to reducing transaction costs for subsequent dealmaking, restricted consultation should therefore have an advantage over open ones. One of the key findings in Barabas' (2004) recent study of deliberation is exactly that the procedural conditions of such processes (i.e. the character of the deliberative forum) affect the results that can be obtained. Clearly there is more to a successful deliberation between stakeholders and decision-makings than a specific institutional framework for conducting it, but the latter can be expected to matter. Moreover, we 
know that many bicameral legislatures resort to conference committees rather than sending legislative amendments back and forth between the chambers to reach legislative deals exactly for the reason that such face-to-face interaction reduces the transaction costs of bargaining and facilitates legislative deal-making (Rasmussen, 2011; Tsebelis and Money, 1997). In a similar manner, many forms of restricted consultation provide a setting where decision-makers and a selected set of external interests can interact directly. Based on the presented arguments, hypothesis 2 is therefore that:

H2: Consultative exercises with open access are likely to result in longer legislative processes than exercises with restrictive access.

In addition to the structure of interest group involvement, we also need to control for other factors in the analysis of legislative duration, which previous research found to be important and which might be related to the existence and type of consultations conducted (Golub, 1999, 2007; Golub and Steunenberg, 2007; Klüver and Sagarzazu, 2011; König, 2007, 2008; Rasmussen and Toshkov, 2011; Schulz and König, 2000; Toshkov and Rasmussen, 2012). Some of the measures from these studies (e.g. whether the EP is involved and the Council decision-making rule) are less relevant for the current study since we analyze co-decision files only (see below). However, other factors related to the degree of political importance and controversy of the proposals must be taken into account by our empirical analyses. Otherwise, we face the risk that our measures of interest group involvement on the proposal simply become another measure of political salience, since all things equal we would expect groups to be more involved on salient than non-salient legislation. Therefore, we need to control for the political importance and controversy of legislative acts, and we do that by including measures of the type and novelty of the EU legislative act, the policy area concerned, the number of EP committees involved, and the number of EP amendments proposed.

\section{Data collection and operationalization}

We test the hypotheses outlined above using data on all proposals submitted to the 2004-09 EP under the co-decision legislative procedure in order to compare the 
legislative duration of proposals that have had (different types of) consultation vis-àvis those that did not involve any consultation of interested parties. The advantage of examining proposals introduced in the 2004-09 period is that we cover a period where a number of the new initiatives and rules to improve European governance (Commission, 2001) and achieve better regulation (2002a, b) had been implemented and were in active use. In order to balance the concerns for the validity and reliability of the data with the need for a large number of cases, we employ a two-step procedure that combines automated data extraction and human coding. Since the details of the data collection procedure might have important implications for the validity of the empirical analyses presented later in this article, we provide an extended discussion of our data collection.

We collected the data and operationalized consultation in the following way. First, we identified all co-decision proposals submitted to the $6^{\text {th }} \mathrm{EP}$ and collected from the Legislative Observatory and PRELEX the relevant information about their legislative duration and a number of other variables, including the number of EP amendments proposed, the responsible Commission DG, the number of EP committees involved, and the type and novelty of the legislative act. Second, we searched through the texts of the proposals and the accompanying explanatory memoranda for mentions of the expression 'consultation with interested parties', which is the heading of the paragraph where the Commission reports on the type of consultation conducted. We also searched for the consult* word-stem which might also signal a consultation. Subsequently, human coders went through all the identified legislative proposals to determine whether consultation had indeed taken place and what the details about the types of consultation were.

Reading the relevant passages from the legislative proposals and explanatory memoranda, we coded (non-exclusively) all cases for the presence of online [146 cases], forum [123], general restricted [116], advisory committees [84], EU agencies [22], management and labor [6], and informal [9] types of consultations, or none at all [252 cases]. The general restricted, advisory committees, EU agencies, management and labor, and informal types were then combined into a single category to which we give the name 'restricted' [188 cases]. This produced three non-exclusive categories with many overlaps (for details, see the Venn diagram in the online appendix). For the final categorization we classified: 
1) cases that had 'restricted' and either 'online' or 'forum' consultation into a 'combined' category [106 cases];

2) cases which had only 'restricted' consultation into a 'restricted' category [82 cases];

3) cases which had either 'online' or 'forum' but no 'restricted' consultation into an 'open' category [91 cases];

4) the residual category is 'no consultation', which includes the proposals where our human coders did not find evidence of consultation of external interests or where neither the expression 'consultation with interested parties' nor the consult* word-stem was found [252 cases].

The table below presents the means, medians and standard deviations of legislative duration for the different types of consultations. Legislative duration is operationalized as the time in days between the Commission's proposals and the signature of the final act. The files which had no consultation have the lowest mean and median, the ones which had only a restricted consultation are in the middle (this group has the highest variability), and 'open' and 'combined' consultations have practically identical means, medians, and standard deviations, and the highest durations.

As mentioned in the previous section, although we are mainly interested in the relationship between consultation and legislative duration, we need to take into account factors like political salience that might render a possible correlation between these two variables spurious. Finding a perfect measure of political salience that is exogenous to interest group involvement and can be obtained for all files in our dataset is far from straightforward. In line with existing literature, we rely on a number of different measures. Taken together, these measures capture different facets of the "the political importance and controversy" of a given file. Hence, the analysis controls for the nature of the act (directive, regulation or decision), whether the act is a new proposal or simply an amendment to an existing EU act, the number of EP amendments tabled at the first reading, the number of EP committees involved in debating the proposal, and the policy area. Hence, these measures are directly related to the importance and controversy of the proposal. Previous research has shown than directives generally require longer deliberation than decisions and regulations, and that new acts are more time-consuming than amendments of existing ones. 
Table 1. Consultation and legislative duration: descriptive statistics

\begin{tabular}{|c|c|c|c|c|}
\hline & & $\begin{array}{l}\text { Number } \\
\text { of cases }\end{array}$ & $\begin{array}{c}\text { Mean/median } \\
\text { (duration in days) }\end{array}$ & $\begin{array}{c}\text { St. deviation } \\
\text { (duration in days) }\end{array}$ \\
\hline No consultation & & 252 & 565 / 461 & 360 \\
\hline \multicolumn{5}{|l|}{ Consultation: } \\
\hline & Open & 91 & 684 / 643 & 322 \\
\hline & Restricted & 82 & $662 / 525$ & 466 \\
\hline & Combined & 106 & $683 / 640$ & 317 \\
\hline
\end{tabular}

Moreover, the higher the degree of controversy reflected in the number of EP amendments the longer we would expect things to take (Toshkov and Rasmussen, 2012). Finally, in line with Reh et al. (2013) we interpret the number of EP committees as a measure of technical complexity rather than political importance. Hence, the fact that a file cross-cuts multiple policy areas does not necessarily imply disagreement or political sensitivity.

\section{Results from the empirical analysis}

The method of analysis we use is Cox proportional hazards regression (a semiparametric form of event history analysis) (Box-Steffensmeier and Jones, 2004). These models are appropriate for our data not only because our dependent variable the number of days between proposal and adoption of legislation - measures duration, but also because we have a substantive number of 'pending' cases $^{5}$ (right-censored observations) which can be accommodated in the framework of survival analysis (Box-Steffensmeier and Jones, 2004) . We opt for the more flexible Cox model instead of the parametric alternatives as we do not have a theoretical expectation about the behaviour of the baseline hazard of legislative adoption over time.

Table 2 reports the results from four Cox survival models: the first one features only the consultation variable and is included for reference, the second one adds controls for the type of act and the policy area (the responsible Commission DG), the third one adds the number of EP amendments, the novelty of the act, and the number of EP committees dealing with the files as well, and the fourth one enters the Commission DG, EP amendments and committees as strata in order to avoid nonproportionality issues. The reported coefficients indicate the effect of the variable on the hazard of legislative conclusion; hence, negative coefficients imply lower chance 
of conclusion (finalization) at any point in time and longer duration of the legislative process.

Table 2. Consultation and legislative duration: Cox proportional hazards models

\section{Model $1 \quad$ Model $2 \quad$ Model 3}

Model 4

Variable

Coeff. (st. error) Coeff. (st. error)

Coeff. (st. error)

Coeff. (st. error)

Type of consultation

(baseline: no consultation)

$\begin{array}{rcccc}\text { Open } & -0.33(0.13) * & -0.74(0.15) * * * & -0.62(0.15) * * * & -0.37(0.20) \\ \text { Restricted } & -0.22(0.13)^{*} & -0.52(0.15) * * * & -0.60(0.15) * * * & -0.42(0.19) * \\ \text { Combined } & -0.38(0.12)^{* *} & -0.78(0.15)^{* * *} & -0.76(0.15) * * * & -0.50(0.20) *\end{array}$

Type of act (baseline: decision)

$\begin{array}{ccccc}\text { Directive } & - & -0.84(0.20) * * * & -0.93(0.21) * * * & -0.67(0.25) * * \\ \text { Regulation } & - & -0.66(0.19) * * * & -0.58(0.20) * * & -0.43(0.24)\end{array}$

Commission DG (24 categories)

Included Included

Strata

Novelty of act (Amendment)

- $\quad$ Included

\begin{tabular}{cccc}
- & - & $0.46(0.12) * * *$ & $0.14(0.14)$ \\
- & - & $-0.02(0.01)^{* * * *}$ & Strata \\
- & - & $0.58(0.11)^{* * *}$ & Strata \\
0.03 & 0.25 & 0.34 & 0.04 \\
531 & 512 & 501 & 501 \\
\hline
\end{tabular}

Number of EP amendments (10)

Number of EP committees

Pseudo R-square

$N$

531

dependent variable - hazard of adoption of a co-decision legislative act. Baseline category for Consultation - 'No consultation'. Baseline category for Type of act - 'Decision'. Model A3S is stratified on Commission DG, EP amendments (dichotomized at the median [25]), and number of EP committees involved (dichotomized at one). Significance levels: $* * *<0.001 ; * *<0.01 ; *<0.05$. $<0.10$

Model 1 indicates that all three types of consultation increase the duration of the legislative process, and in the case of open and combined consultations, the effect is 
statistically significant. The occurrence of open consultations is associated with a $28 \%$ decrease in the daily hazard of adoption, and the occurrence of combined (open and restricted) consultations is associated with a $32 \%$ reduction. Although the coefficient for restricted consultations is smaller, the differences between the different types of consultations are not significant (see the online appendix for formal tests). It could be, however, that the types of acts that do get a consultation are different than the types of acts that do not. Therefore, in model 2 we include two important control variables the type of legislative act (decision, directive, or regulation) and the responsible Commission DG (which controls for the policy area of the proposal). According to this model, all types of consultations significantly increase legislative duration, and the effects are much bigger than the estimates from the model without the control variables: open and combined consultations now lead to a more than $50 \%$ decrease in the daily hazard of legislative adoption compared to the 'no consultation' baseline category. Model 3 includes several more control variables - the novelty of the acts, the number of EP amendments proposed during $1^{\text {st }}$ reading, and the number of EP committees involved ${ }^{6}$. According to the model, consultation still significantly increases legislative duration for all three types. The daily hazard of adoption is between $45 \%$ and $55 \%$ lower depending on the type of consultation conducted, but the differences between the types are still not significant. Hence, we cannot find support for the argument that open forms of consultations last significantly longer than restricted consultations.

In order to get a better sense of the scale of the effects, Figure 1 plots the predicted survival curves over time for files under no consultation and files under both open and restricted consultation. The predictions are based on Model 3 with the covariates set at typical values. We can see from the figure that two years after a proposal, $80 \%$ of the non-consulted files but only just over $50 \%$ of the consulted files have been finalized. It takes approximately 21 months for $75 \%$ of the non-consulted files to be adopted while it takes approximately 34 months for the same proportion of consulted files to be adopted. The effect sizes appear substantively important from these comparisons. 
Figure 1. Predicted survival for files under no consultation and under both open and restricted consultation. Estimates based on Model 3 [other covariates: new directive in the field of Internal Market, average number of EP amendments, one EP committee involved].

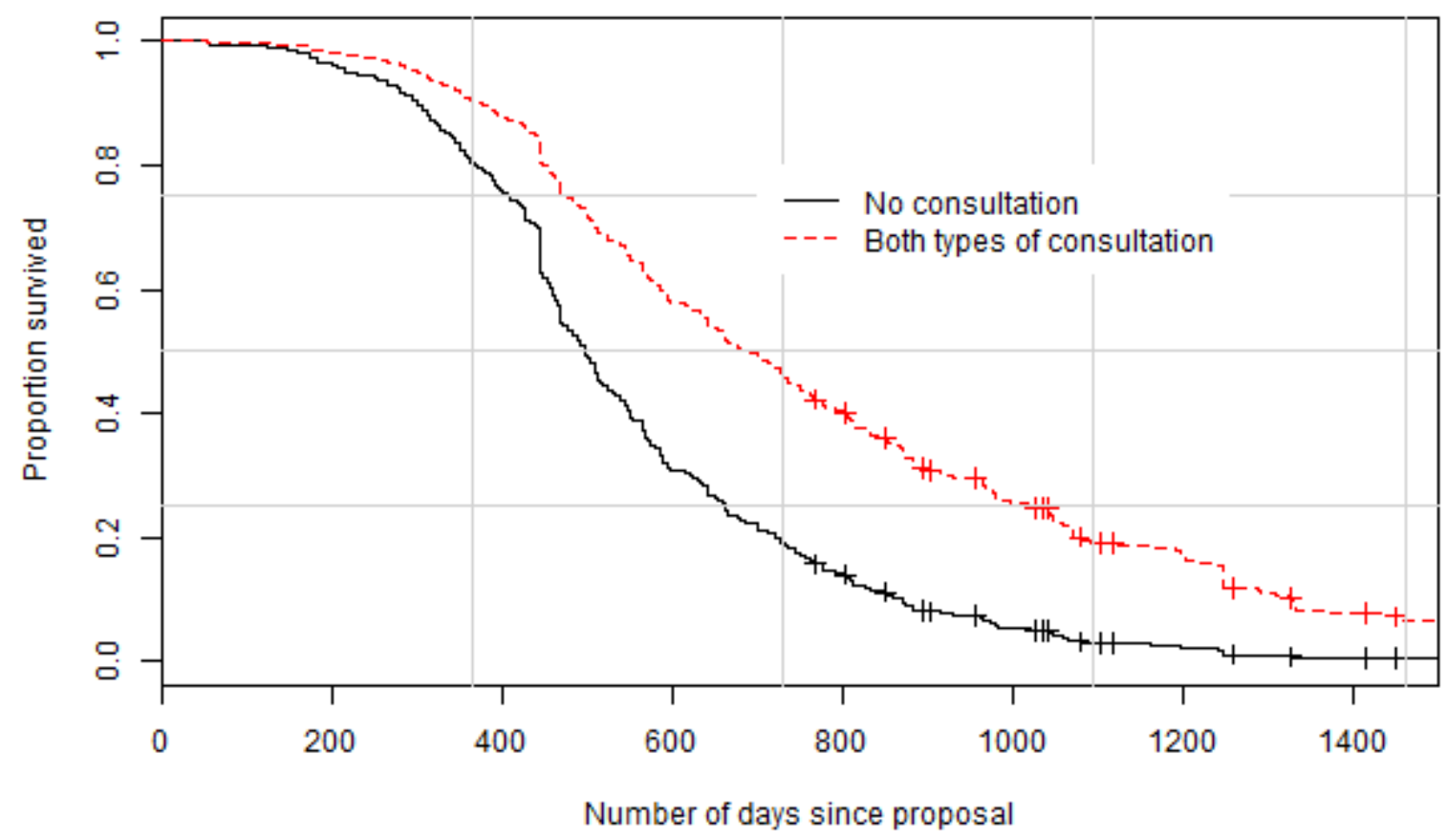

Turning to the control variables, directives and to a lesser extent regulations take significantly longer than decisions, and the number of EP amendments proposed also increase the length between proposal and adoption. The involvement of more EP committees increases legislative speed. The involvement of multiple committees may help prepare the ground better, or include a more varied set of views, which means that the legislative act can be adopted faster. Moreover, multiple committees are often used in the case of technical legislation, which may not be highly politically salient.

The Cox survival models need to satisfy the assumption of proportionality (Box-Steffensmeier and Jones, 2004). However, the formal tests for nonproportionality (Grambsch and Therneau, 1994) of the full model (3) indicate that the effects of the number of EP amendments and committees involved, as well as some categories of the responsible Commission DG might violate the assumption of proportionality $^{7}$ (see the appendix for details). Although non-proportionality does not affect our main independent variable of interest - the type of consultation - we still need to correct for the non-proportionality of the model. 
We first employed the most often-used approach to correct non-proportionality, i.e. interacting the offending variables with a function of time. Our online appendix includes a thorough overview and discussion of the conducted tests. Unfortunately, this method was not suitable in our case. A closer inspection and refitting of the models to different subsets of the data reveal that the non-proportionality problem is confined mostly to the observations with very long durations (for details see the online appendix). Hence, we do not include interactions with time since they will provide misleading inferences about the entire dataset, but we note that the models have a worse fit, and the effect of the variables drops and loses significance for observations with (very) long durations. Such extremely long cases are likely to be a product of inter-institutional gridlock for reasons having little to do with consultations, so it is not entirely surprising that the effect of consultation on duration is different for these outliers.

Instead, we opted for an alternative approach to correct non-proportionality, i.e. to stratify the model over the offending variables effects. The results are reported in the right-most column of Table 2 (Model 4). The estimated coefficients for different types of consultation remain statistically significant and in the expected direction, but their sizes drop and the uncertainty about the estimates increases because in this model the information is not pooled over strata. Stratifying the model solves the nonproportionality issues for all remaining variables and the model as a whole (see the appendix for the formal tests).

Finally, we also used a third method of correcting non-proportionality, i.e. we fitted a non-parametric log-logistic survival model, which does not require the assumption of proportionality (for details see the appendix). The results support the inferences derived on the basis of the Cox model

In addition to dealing with violations of the non-proportionality assumptions we also conducted a matching analysis to check how sensitive our results are to the fact that files on which consultation occurs may not be similar to files where it does not with respect to the background characteristics. We control for these background characteristics in our models. The idea is that by including such possible omitted background characteristics variables in the equation for legislative duration we increase our confidence that the positive effect of consultation on duration is not a statistical artefact. In essence, the inclusion of these control variables tries to approximate the counterfactual situation for legal proposals that are similar in all 
other respects but differ only in the occurrence or non-occurence of consultation with interest groups. This approach is reasonable if the dataset is well-balanced meaning that there is a sufficient overlap between the treatment (consultation) and baseline (no consultation) groups in terms of the background characteristics (control variables). If the overlap is limited, however, the inferences presented above might be misleading (Gelman and Hill, 2007). In order to account for this possible threat to the conclusions we complemented the analysis of the full dataset presented above with a 'matching' analysis that explicitly adjusts the treatment and the control group vis-à-vis background characteristics of the legal acts (Ho et al., 2007, 211). The results from the matching analysis, reported in the online appendix, support the conclusion that consultations with interested parties significantly increase legislative duration and provide the additional safeguard that the results are not driven by imbalances in the data.

\section{Discussion}

Our empirical finding that there is no significant difference in the effect of open and restricted forms of consultation on duration is surprising, since the latter are often portrayed as more efficient ways of hearing the public involving a smaller set of experts in a closed forum in the literature. The lack of variation in duration may result from the fact that the differences between the formats and participants in open and restricted consultations are not as clear-cut as the literature would lead us to expect. Even if it might generally be the case that open consultation attract a higher and more conflictual set of participants that are less experienced, and that these consultations are conducted in a set-up which may involve higher transaction costs than the restricted ones, there will always be variation within these categories.

Moreover, some of the textbook accounts of what the philosophy behind these different types of consultation is may not hold in practice. Even if open consultations are supposed to give the general public an option to voice its opinion, there are clear limits in practice as to who participates in "open consultations". Research shows that the contributions to open consultations from individuals are relatively limited and that business interests dominate among the interest group participants (see e.g. Quittkat, 2011; Rasmussen and Carroll, forthcoming). Hence, even if everyone can in principle participate in open consultations, resources and experience are also likely to play a key role as they do for gaining access in general (see e.g. Eising, 2007). Effectively 
this means that the characteristics of the players who end up participating in open and restricted consultations may not be so different after all. Many of the participants in open consultations are also experienced brokers with substantial expertise and degree of familiarity with consultation. Therefore, the open consultations may not give rise to substantially higher transaction costs for reaching the subsequent legislative deals than restricted ones. This is even more so if open consultations remain 'empty shells' and are not taken seriously by the institutions.

Moreover, some of these expected differences between restricted and open consultation formats can be expected to be smaller in the EU than other political systems. The EU is not a corporatist system, but one where the Commission is under the obligation to consult a broad and representative set of interests no matter whether the form of consultation is restricted or not (European Commission, 2002b). One of the most frequent uses of restrictive consultations in this system, Commission advisory committees, tend to consist of a very high number of participants of many different types representing many different views (Gornitzka and Sverdrup, 2010; Rasmussen and Gross, 2012) ${ }^{8}$. In this way, many restricted consultations in the EU do not provide a small interactive environment where deals can easily be reached among a few insiders.

In order to explore some of these possibilities, we have complemented our large-n approach by carrying out a small pilot study of whether there is a linkage between the number and diversity of the consultation participants and legislative duration on a smaller number of Commission online consultations, which had subsequently led to completed legislation. Based on these cases we do not have grounds for concluding that the density and diversity of the consultation participants affect duration. In the future, more systematic analyses of specific consultative exercises and their participants are needed. Our preliminary findings indicate that rather than gathering information about the number and diversity of active interests in a given consultative exercise, such research should include information about the actual preference heterogeneity of the actors involved in the specific proposals. As mentioned in our theoretical background, spatial theory would predict that the degree of actual preference conflict among the participants - rather their sheer number and organisational type - affects the prospects of a joint decision. 


\section{Conclusion}

Even though modern liberal democracies have developed a range of mechanisms for consulting external interests over the years, little research has examined the effect of stakeholder involvement on the legislative processes or on the policy outcomes. We have analyzed how the involvement of external actors in legislative preparation affects the speed with which decision-makers respond to citizen demand and adopt legislation. Using direct regression and matching techniques we find that legislative preparation involving interest groups before a formal proposal is introduced increases rather than decreases the duration of the subsequent legislative processes.

In this way, consultation of external actors does not have the purported beneficial effects for the duration of the legislative process. External actor involvement does not clear potential later conflicts between the decision-makers, but seems to increase the transaction costs of bargaining by requiring the decision-makers to spend more time to form the necessary coalitions to reach legislative deals subsequently.

Of course, the longer duration of the legislative process is not necessarily a bad outcome. The benefits of consultation in terms of accommodating the preferences of different actors and improving the quality and democratic legitimacy of legislation might well outweigh the potential losses of slowing down the policy-making processes. Nevertheless, our work shows that some of the concerns voiced by the EP, that consultations might lead to delays in the adoption of legislation cannot be ruled out. These concerns demonstrate that, for a democratically elected institution, responsiveness is not simply about giving the public what it wants but also about providing such outputs in a timely fashion. If the policy-making system takes too long, the reached compromises may not longer achieve their aims because the character of the problems they were meant to address could have changed and/or the views of the public may be different. In addition, legislators operate under a time constraint meaning that time spent on certain policies cannot be devoted to others.

At the same time, the concerns expressed by the EP towards the Commission's White Paper regarding many of the "newer consultative tools" providing open access for external actors seem less relevant. Hence, even if the EU has launched many new tools for involving external actors that involve and inclusive access, these types of consultation are not different in terms of legislative speed from restricted consultations. These findings hold even when we control for important additional 
attributes of the negotiated files relating to their degree of political importance and controversy.

Future research should extend our line of research here investigating in more detail what the possible mechanisms are through which these different formats of external actor involvement slow down the passage of legislation. Such research should contain measures of the experience and background of the participants involved and the format and agendas of specific consultative exercises. It is highly needed to judge the effects of the increasing amount of resources spent on external actor involvement in policy preparation, not just in the EU but worldwide, on policy-making legitimacy and efficiency.

1 For a description of the distinction between input and output legitimacy, see (Scharpf, 1999).

${ }^{2}$ The normative implications of consulting stakeholders are a matter of a long-lasting and intense debate in the academic literature. There is for example no lack of accounts of how interest groups act as instruments of "greed and selfishness" rather than defenders of the general public interest (Kollman, 1998; Lowery and Brasher, 2004).

${ }^{3}$ This means that when a public authority participates in a consultative exercise of another public authority it is also regarded as an "external actor" or a "stakeholder".

${ }^{4}$ In fact, this argument is the one that the EU institutions have used to explain why a higher share of legislation in the EU co-decision procedure is reconciled early: "Perhaps the major factor is the trend to prepare more exhaustively the 1st reading (through evaluation of the Commission's Impact assessment, systematic evidence gathering, studies, public hearings, etc.)" (2009: 41).

${ }^{5}$ In the dataset used in the analysis, 43 cases are classified as pending (ongoing). Initially, this category was bigger but we manually checked each non-completed dossier to establish whether it was indeed 'ongoing', or it had no final date of approval due to withdrawals of the proposal, change of legislative procedure, or simply a mistake in the Legislative Observatory database.

${ }^{6}$ We also tried out models that included the number of recitals, the month of the proposals, and the number of legal bases. None of these additional controls showed substantive effects and, more importantly, none of them changed the inference for our main variables of interest: the existence and type of consultation.

${ }^{7}$ The formal tests conducted indicate problems with some of the categories of the main independent variable in Models 1 and 2. However, a failure to reject the hypothesis of non-proportionality might result from misspecified models (omitted variables and/or wrong functional forms for the independent variables included) as well as from non-proportionality (Keele, 2010, pp.192-3). This is why we focus our attention on the full model (3).

${ }^{8}$ Another theoretical reason that the open consultations do not last longer than the restricted ones might be that the impact assessment, with which they are often combined, reduced transaction costs in the subsequent policy process and thus counteracted any positive effect the open consultation might have had. However, we are skeptical about this view. Hence, impact assessment is not only combined with open consultations. Moreover, in practice it would be virtually impossible to separate the effect of consultative exercises from impact assessment in general since almost all impact assessments involve some form of consultation (Renda 2006). 


\section{References}

Abelson J, Forest P-G, Eyles J, Smith P, Martin E and Gauvin F-P (2003) Deliberations about deliberative methods: Issues in the design and evaluation of public participation processes, Social Science \&amp; Medicine 57(2): 239-51.

Andersen S and Eliassen K (eds) (1993) Making policy in Europe. London: Sage Publications.

Barabas J (2004) How deliberation affects policy opinions, American Political Science Review 98(04): 687-701.

Bennett R J (1997) The impact of European economic integration on business associations: The UK case, West European Politics 20(3): 61-90.

Beyers J, Eising R and Maloney W (2008) Researching interest group politics in Europe and elsewhere: Much we study, little we know?, West European Politics 31(6): 1103-28.

Bishop P and Davis G (2002) Mapping public participation in policy choices, Australian Journal of Public Administration 61(1): 14-29.

Bouwen P (2004) Exchanging access goods for access: A comparative study of business lobbying in the European Union institutions, European Journal of Political Research 43(3): 337-69.

Box-Steffensmeier J M and Jones B S (2004) Event history modeling. A guide for social scientists. Cambridge: Cambridge University Press.

Coen D (1997) The evolution of the large firm as a political actor in the European Union, Journal of European Public Policy 4(1): 91-108.

Coen D (2007) Empirical and theoretical studies in EU lobbying, Journal of European Public Policy 14(3): 333-45.

Coen D and Richardson J (2009) Lobbying the European Union institutions, actors, and issues. Oxford: Oxford University Press.

Commission E. (2001). European governance. A white paper.

Commission E. (2002a). European governance: Better lawmaking.

Commission E. (2002b). Towards a reinforced culture of consultation and dialogue - general principles and minimum standards for consultation of interested parties by the commission.

Coughlin P J, Mueller D C and Murrell P (1990) Electoral politics, interest groups, and the size of government, Economic Inquiry 28(4): 682-705.

Dahl R A (1961) Who governs? New Haven: Yale University Press.

Delli Carpini M X, Cook F L and Jacobs L R (2004) Public deliberation, discursive participation, and citizen engagement: A review of the empirical literature, Annual review of political science 7(1): 315-44.

Easton D (1971) Political system. An inquiry into the state of political science. New York: Alfred A. Knopf.

Eising R (2007) Institutional context, organizational resources and strategic choices, European Union Politics 8(3): 329-62.

Eising R (2008) Interest groups in EU policy-making, Living Reviews in EU Governance 2008(4): http://europeangovernance.livingreviews.org/Articles/lreg-2008-4/

European Parliament. (2001). Report on the commission white paper on European governance.

Gaffney J (1996) Political parties and the European Union. London: Routledge.

Gelman A and Hill J (2007) Data analysis using regressson and multilevel/hierarchical models. Cambridge: Cambridge University Press.

Golub J (1999) In the shadow of the vote? Decision making in the European community, International Organization 53(4): 733-64. 
Golub J (2007) Survival analysis and European Union decision-making, European Union Politics 8(2): 155-79.

Golub J (2008) The study of decision-making speed in the European Union: Methods, data and theory, European Union Politics 9(1): 167-79.

Golub J and Steunenberg B (2007) How time affects EU decision-making European Union Politics 8(4): 555-66.

Gornitzka $\AA$ and Sverdrup U (2008) Who consults? The configuration of expert groups in the European union, West European Politics 31(4): 725-50.

Gornitzka $\AA$ and Sverdrup U (2010) Access of experts: Information and EU decision-making, West European Politics 34(1): 48-70.

Grambsch P and Therneau T (1994) Proportional hazards tests and diagnostics based on weighted residuals, Biometrika 81: 515-26.

Gray V and Lowery D (1995) Interest representation and democratic gridlock, Legislative Studies Quarterly 20(4): 531-52.

Gray V and Lowery D (2000) The population ecology of interest representation. Michigan: Michigan University Press.

Greenwood J (2011) Interest representation in the European Union. London: Palgrave.

Greenwood J, Grote J and Ronit C (1992) Organized interests and the European community. London: Sage.

Gross A and Rasmussen A (2012) 'Do insiders bias representation: Exploring access to the commission's advisory committees', Paper presented at the ECPR Joint Sessions in Antwerp, April 2012.

Heinz J P, Laumann E O, Nelson R L and Salisbury R (1993) The hollow core. Cambridge: Harvard University Press.

Ho D E, Imai K, King G and Stuart E A (2007) Matching as nonparametric preprocessing for reducing model dependence in parametric causal inference, Political Analysis 15(3): 199-236.

Keele L (2010) Proportionally difficult: Testing for nonproportional hazards in cox models, Political Analysis 18(2): 189-205.

Kenworthy L (2003) Quantitative indicators of corporatism, International Journal of Sociology 33(3): 10-44.

Klüver H (2011) Lobbying in coalitions: Interest group influence on European Union policymaking, Nuffield College Working Papers in Politics 2011(4): 1-36.

Klüver H (forthcoming) Lobbying in the European Union: Interest groups, lobbying coalitions and policy change. Oxford: Oxford University Press.

Klüver H and Sagarzazu I (2011) 'Ideological congruency and duration of policy-making: The effect of partisanship across EU institutions', Paper prepared for presentation at the 1st Annual General Conference of the European Political Science Association, Dublin, 1618 June 2011.

Klüver H and Sagarzazu I (forthcoming) Ideological congruency and decision-making speed: The effect of partisanship across EU institutions, European Union Politics.

Kohler-Koch B (1994) Changing patterns of interest intermediation in the European Union, Government and Opposition 29(2): 166-80.

Kollman K (1998) Outside lobbying. Public opinion and interest group strategies. Princeton: Princeton University Press.

König T (2007) Divergence or convergence? From ever-growing to ever-slowing European legislative decision making, European Journal of Political Research 46: 417-44. 
König T (2008) Analysing the process of EU legislative decision-making : To make a long story short..., European Union Politics 9(1): 145-65.

König T, Lindberg B, Lechner S and Pohlmeier W (2007) Bicameral conflict resolution in the European Union: An empirical analysis of conciliation committee bargains, British Journal of Political Science 37: 281-312.

Lindberg B, Rasmussen A and Warntjen A (eds) (1998) The role of political parties in the European Union: Special issue of the Journal of European Public Policy 15(8).

Lowery D and Brasher H (2004) Organized interests and american government. New York: McGraw Hill.

Mahoney C (2008) Brussels versus the beltway. Washington DC: Georgetown University Press.

Mair P (2006) 'Political parties and party systems', in P Graziano and M Vink (eds) Europeanization: New research agendas pp. 154-66. London: Basingstoke: Palgrave Macmillan.

Mueller D G and Murrell P (1986) Interest groups and the size of government, Public Choice 48(2): 125-45.

Olson M (1982) The rise and decline of nations. New Haven: Yale University Press.

Paterman C (1970) Participation and democratic theory. Cambridge: Cambridge University Press.

Quittkat C (2011) The European commission's online consultations: A success story?, JCMS: Journal of Common Market Studies 49(3): 653-74.

Rasmussen A (2011) Procedural (dis)obedience in bicameral bargaining in the united states and the European Union, Journal of European Integration 33(3): 267-83.

Rasmussen A and Carroll B (forthcoming) Determinants of upper-class dominance in the heavenly chorus: Lessons from European commission online consultations, British Journal of Political Science.

Rasmussen A and Gross V (2012) 'Do insiders bias representation: Exploring access to the commission's advisory committees', Paper presented at the ECPR Joint Sessions in Antwerp, April 2012.

Rasmussen A and Toshkov D (2011) The inter-institutional division of power and time allocation in the European parliament, West European Politics 34(1): 71 - 96.

Reh C, Heritier A, Bresssanelli E and Koop C (2013) The informal politics of legislation: Explaining secluded decision making in the European Union, forthcoming Comparative Political Studies.

Salisbury R (1992) Interests and institutions: Substance and structure in american politics. Pittsburgh: University of Pittsburgh Press.

Scharpf F (1999) Governing in Europe: Effective and democratic. Oxford: Oxford University Press.

Schmitter P (1979) 'Still the century of corporatism? ', in P Schmitter and G Lehbruch (eds) Trends towards corporatist intermediation. New York: Sage.

Schneider G, Finke D and Baltz K (2007) With a little help from the state: Interest intermediation in the domestic pre-negotiations of EU legislation, Journal of European Public Policy 14(3): 444 - 59.

Schulz H and Konig T (2000) Institutional reform and decision-making efficiency in the European Union, American Journal of Political Science 44(4): 653-66.

Schulz H and König T (2000) Institutional reform and decision-making efficiency in the European Union, American Journal of Political Science 44(4): 653-66. 
Streeck W, Grote J, Schneider V and Visser J (2006) Governing interests: Business associations facing internationalization London: Routledge.

Streeck W and Kenworthy L (2005) 'Theories and practices of neo-corporatism', in T Janoski, R R Alford, A M Hicks and M A Schwartz (eds) A handbook of political sociology: States, civil societies and globalization. New York: Cambridge University Press.

Toshkov D, Lowery D, Carroll B and Berkhout J (forthcoming) Timing is everything? Organized interests and the timing of legislative activity, Interest Groups and Advocacy.

Toshkov D and Rasmussen A (2012) 'Time to decide: The effect of early agreements on legislative duration in the European Union', in D Naurin and A Rasmussen (eds) Linking inter- and intrainstitutional change in the European Union. London: Routledge.

Truman D B (1971) The governmental process. New York: Knopf.

Tsebelis G and Money J (1997) Bicameralism. Cambridge: Cambridge University Press.

Walker J L (1983) The origins and maintenance of interest groups in america, The American Political Science Review 77(2): 390-406. 